\title{
Identification of a genetic marker associated with the resistance to Schistosoma mansoni infection using random amplified polymorphic DNA analysis
}

\author{
Abdel-Hamid Z Abdel-Hamid/ ${ }^{+}$, Sayed M Rawi*, Azza F Arafa \\ Medicinal Chemistry Department, National Research Centre, Dokki 12622, Cairo, Egypt \\ *Zoology Department, Faculty of Science, Cairo University, Egypt
}

\begin{abstract}
In schistosomiasis, the host/parasite interaction remains not completely understood. Many questions related to the susceptibility of snails to infection by respective trematode still remain unanswered. The control of schistosomiasis requires a good understanding of the host/parasite association. In this work, the susceptibility/resistance to Schistosoma mansoni infection within Biomphalaria alexandrina snails were studied starting one month post infection and continuing thereafter weekly up to 10 weeks after miracidia exposure. Genetic variations between susceptible and resistant strains to Schistosoma infection within B. alexandrina snails using random amplified polymorphic DNA analysis technique were also carried out. The results showed that $39.8 \%$ of the examined field snails were resistant, while $60.2 \%$ of these snails showed high infection rates. In the resistant genotype snails, OPA-02 primer produced a major low molecular weight marker $430 \mathrm{bp}$. Among the two snail strains there were interpopulational variations, while the individual specimens from the same snail strain, either susceptible or resistant, record semiidentical genetic bands. Also, the resistant character was ascendant in contrast to a decline in the susceptibility of snails from one generation to the next.
\end{abstract}

Key words: schistosomiasis - Biomphalaria - DNA random amplified polymorphic DNA (RAPD)

Schistosomiasis is considered the second most prevalent world wide parasitic disease ranked next to malaria. It has significant economic and public health consequences in many developing countries especially Egypt. Economical development and improvement of living standards in these endemic countries depends on the elimination or eradication of this disease. Although attempts at control have been proposed by international, national, and private agencies, effective absolute permanent results have not yet been achieved. There is thus need to apply methods for effective control in conjunction with chemotherapy or vaccine development along with different molluscicides for snail control.

Egypt is one of the most highly endemic areas in the world with infection rates exceeding 80\% (5-6 million) in some localities in the Nile Valley (El-Khoby et al. 1998). Biomphalaria alexandrina snail as specific intermediate host of Schistosoma mansoni are prevalent in both upper and lower Egypt, but during the last decade, it became the most dominant species in the Nile Delta forming a main threat for schistosomiasis transmission in the North of Egypt. This snail species invades the irrigation areas and drainage systems and also water sources in reclaimed areas leading to infection in previously uninfected populations which eventually leads to increase schistosomiasis transmission in Egypt.

+Corresponding author: abdelhamidzaki@hotmail.com Received 22 May 2006

Accepted 1 November 2006
Since the development of the Schistosoma parasite in the intermediate host snail is influenced by a number of parasite and snail genes as reported by Richards and Shade (1987) and Rollinson et al. (1998), genetic control of the snails plays an important role in schistosomiasis control. A growing interest revolves around identifying the products of the snail and parasite genes influencing these associations. Previous studies have demonstrated the great variability in the suitability of different snail genera and species to act as carriers for $S$. mansoni species (Abdel-Hamid et al. 1999, Spada et al. 2002, Da Silva et al. 2004, Lotfy et al. 2005). An understanding of these interactions is important to aid future attempts to control and possibly reduce morbidity caused by Schistosoma parasite.

For genetic control of schistosomiasis, one strategy is based on the premise that snails resistant to parasitic infection could be used as biological competitors to replace existing susceptible snails in endemic areas (Coelho et al. 2004). This approach however, requires a more thorough understanding of the genetics of the complex interrelationship between parasites and snails.

Starting from the early 1990s, there has been an increasing interest in the developing of genetic on snail species in order to change the susceptibility of natural snail population from being predominantly highly susceptible to a non-susceptible state, through the release of refractory snails into natural habitats (Joubert et al. 1991, Knight et al. 1999, Spada et al. 2002, Da Silva et al. 2004, Rosa et al. 2004).

The present study emphasizes our interest in snail genetics to identify molecular markers associated with resistance to the parasite in the snail host by genetic crosses between parasite-resistant and susceptible iso- 
gonics snails. Both the identification of genetic markers for resistance and a detailed definition of the population structure of the snails are important for understanding the epidemiology of schistosomiasis in endemic areas. In this work, random amplified polymorphic DNA analysis technique is used for genetic analysis of DNA genome of $B$. alexandrina snails, in an attempt to associate possible polymorphic markers related to susceptibility/resistance to $S$. mansoni infection.

\section{MATERIALS AND METHODS}

Intermediate host snails - The snails were originated from Delta region at Egypt. They were selected on the basis of health and size and have been maintained for one year in the laboratory under suitable environmental conditions. The methods of separating Schistosoma resistant and susceptible strains from $B$. alexandrina snails is performed according to the method described by Zanotti-Magalhaes et al. (1997) with some modifications as follows: each time 100 juvenile snails were exposed individually for $4 \mathrm{~h}$ to 10 freshly hatched miracidia of Egyptian S. mansoni strain obtained from Schistosoma Biological Supply Project, Theodur Bilharz Research Institute, Egypt in vials containing $3 \mathrm{ml}$ water. A dose of 10 miracidiae can be considered as a high dose for $B$. alexandrina snails, minimizing the risk of the residual variability of the strain of S. mansoni. Each tested snails was returned and reared singly in a beaker contains 400 $\mathrm{ml}$ snail conditioned water (SCW). Snails were held for cercarial emergency for 10 weeks post-exposure to avoid any missing could delayed development of the parasite. Snails in which developing parasites are not evident were re-exposed individually to a high dose of miracidia (10/ snail). Any snails in which infections observed were considered susceptible and those that remained uninfected after three exposures were considered resistant.

In selecting for resistant stocks, snails that remained uninfected after three exposures (10 miracidiae/snail) were isolated and reared singly for self-reproduction. Also, in selecting for susceptible stocks, unexposed progeny of snails from which exposed test groups yielded high infection rates, were isolated and reared singly for selfreproduction under laboratory condition. These selffertilized resistant and susceptible snails were used in the present study as parent stocks for breeding the successive generations $\left(\mathrm{F}_{1}\right.$ and $\left.\mathrm{F}_{2}\right)$. Crosses were obtained by placed snails pairing in $1000 \mathrm{ml}$ containers containing $800 \mathrm{ml} \mathrm{SCW}$. Individuals from resistant and susceptible snails were used in the present study to identify (RAPD) fragments that might be associated with resistance.

DNA extraction - DNA was extracted from the tip of the head foot region of individual snails (resistant and susceptible strains), using lysis buffer containing 2\% CTAB (Winnepenninckx et al. 1993 and modified by AbdelHamid et al. 1999). DNA concentration and purity was determined spectrophotometrically at 260 and $280 \mathrm{~nm}$ and also by using $2 \%$ agarose gel electrophoresis.

$D N A$ amplification by RAPD-PCR - The genotypes of the resistant and susceptible strains of $B$. alexandrina snails were determined with different arbitrary 10-mer primers by RAPD-PCR technique as the method described by Simpson et al. (1993), with some modifications: 2 ng of DNA genome were amplified with a PTC 200 (Peltier thermal cycler) MJ Research, US. Each reaction was carried out in a final volume of $10 \mu 1$ containing 1 unit Taq DNA polymerase (Gibco BRL, MD, US), $1 \times$ PCR buffer, $0.2 \mathrm{mM}$ of each dNTP, and 7 pmol of each random primer (Gibco). The amplification conditions were as follows: 1 cycle at $95^{\circ} \mathrm{C}$ for $5 \mathrm{~min}$, 2 cycles at $95^{\circ} \mathrm{C}$ for $30 \mathrm{~s}$, at $30^{\circ} \mathrm{C}$ for $2 \mathrm{~min}$ and at $72^{\circ} \mathrm{C}$ for $1 \mathrm{~min}$, and 33 cycles during which the annealing temperature was changed to $40^{\circ} \mathrm{C}$ and the time of the extension step was increased to 5 min during the final cycle.

After DNA thermal cycle, PCR products were analyzed by gel electrophoresis and silver staining to resolve amplified fragments as described by Santos et al. (1993). Genetic variability of the susceptible and resistant strains was evaluated by analyzing the electrophoretic band patterns obtained on the gels.

\section{RESULTS}

Susceptibility/resistance of Biomphalaria snails to Schistosoma infection - Susceptibility or resistance to $S$. mansoni infection within $B$. alexandrina snails were studied starting four weeks post infection and continuing thereafter weekly up to 10 weeks after miracidia exposure. The results pointed out that about $39.8 \%$ of the examined snails were resistant, in contrast with $60.2 \%$ of these snails yielded high infection rates as shown in Fig. 1. The curves representing percentages of susceptible snails started at 6th week post infection and reached the highest peaks by approximately the 8 th week. While the curves of refractory snails gradually decreasing toward the 8th week and up to the 8th week post infection no changes in percentages of refractory snails occurred, and no differences were noted at that time up to the 10th week. The ratio of susceptibility/resistance within the same snail stock at a time was fixed, although the number of snails could change depending on the increasing of mortality within susceptible ones.

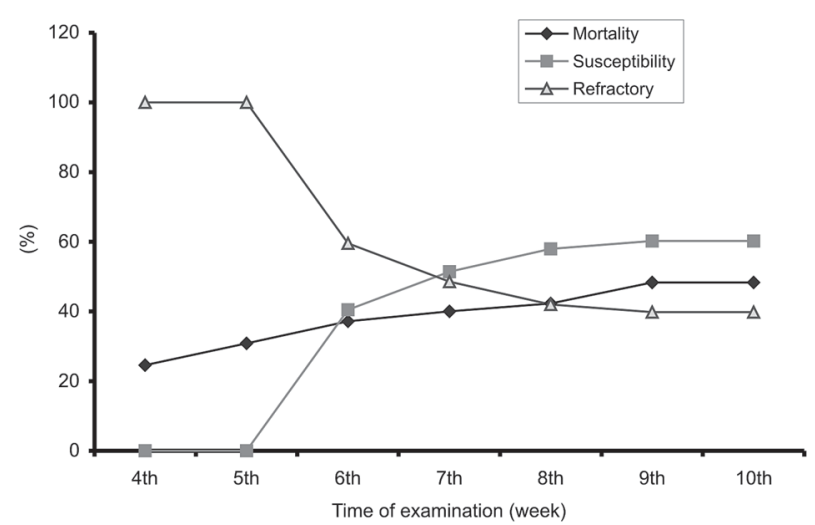

Fig. 1: weekly cumulative percentage of mortality and susceptibility/refractory of parental Biomphalaria alexandrina snails to Schistosoma mansoni infection starting 4 th week post infection. 
The preliminary results of the present experiment showed that our laboratory population of the original parental stock of $B$. alexandrina snails upon first exposure with its homologous strain of $S$. mansoni is not completely susceptible and tends to be partially resistant (refractory) to infection. Also, resistant character was ascendant in contrast to a decline in the susceptibility of snails from one generation to the next as shown in Fig. 2.

From genetic point of view, the results showed the utility of the RAPD-PCR method for differentiation of snail lines of $B$. alexandrina. The snail lines were selected on the basis of well characterized resistance/susceptibility phenotypes upon exposure to S. mansoni. Accordingly, before marking on the RAPD study described, a major concern was that the assay would produce a certain degree of polymorphic information with laboratory-maintained lines of $B$. alexandrina, thus providing inconsistent data for strains differentiation. We found that with one of the 14 used primers, OPA-02, the method was reliable for producing species specific RAPD profiles for the genus B. alexandrina and for the identification of stable genetic markers between the two strains within the same snail species.

Despite the homogeneity of most bands, among susceptible and resistant strains within B. alexandrina snail species, the genomic DNA, amplified with primer OPA- 02 presented a polymorphic band of nearly $430 \mathrm{bp}$, in the resistant lineages only as shown in Fig. 3.

Several different clonal stocks derived from our laboratory bred $B$. alexandrina snails by selection for certain genetic character were employed. Subsequent studies involving both crosses and selfing of two different parental strains (susceptible and resistant) for two successive generations, we obtained four various snail stocks in $\mathrm{F}_{1}$ generation and eight various stocks in $\mathrm{F}_{2}$ generation. In the present study, results obtained upon exposure of 30 offspring of the 12 snail groups indicate that snails derived by selfing (either susceptible or resistant) exhibits higher percentage of susceptibility or resistant than those derived by crossing. From 39.8\% resistant parental snail stock, $87 \%$ of the interbreeding

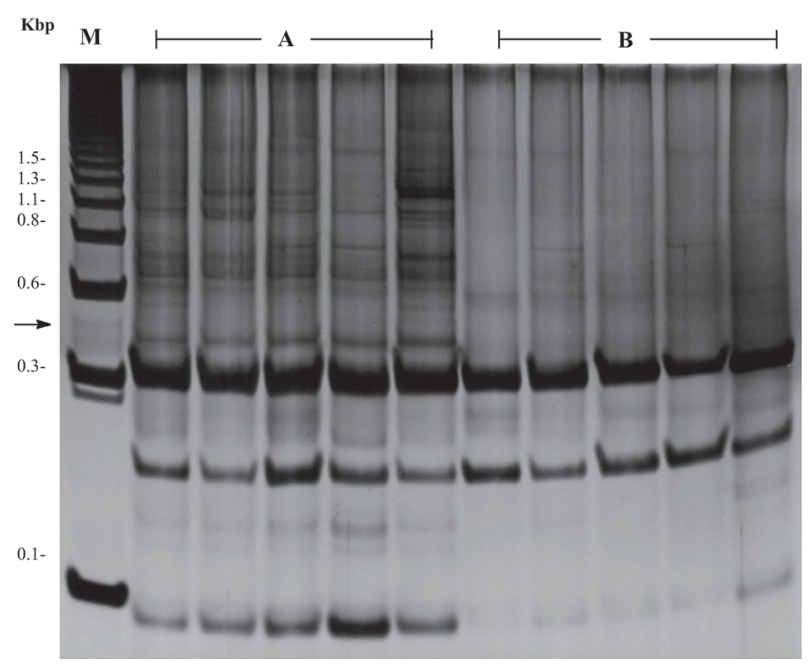

Fig. 3: $6 \%$ silver stained polyacrylamide gel showing the random amplified polymorphic DNA profiles obtained with primer OPA-O2 and $2 \mathrm{ng}$ of DNA genome extracted from two different strains of $F_{1}$ progeny of Biomphalaria alexandrina snails. M: 123 bp DNA ladder; A: five individuals of $\mathrm{F}_{1}$-resistant strain; $\mathrm{B}$ : five individuals of $\mathrm{F}_{1}$-susceptible strain; arrow indicates the position of specific resistant-marker at $430 \mathrm{bp}$ fragment.

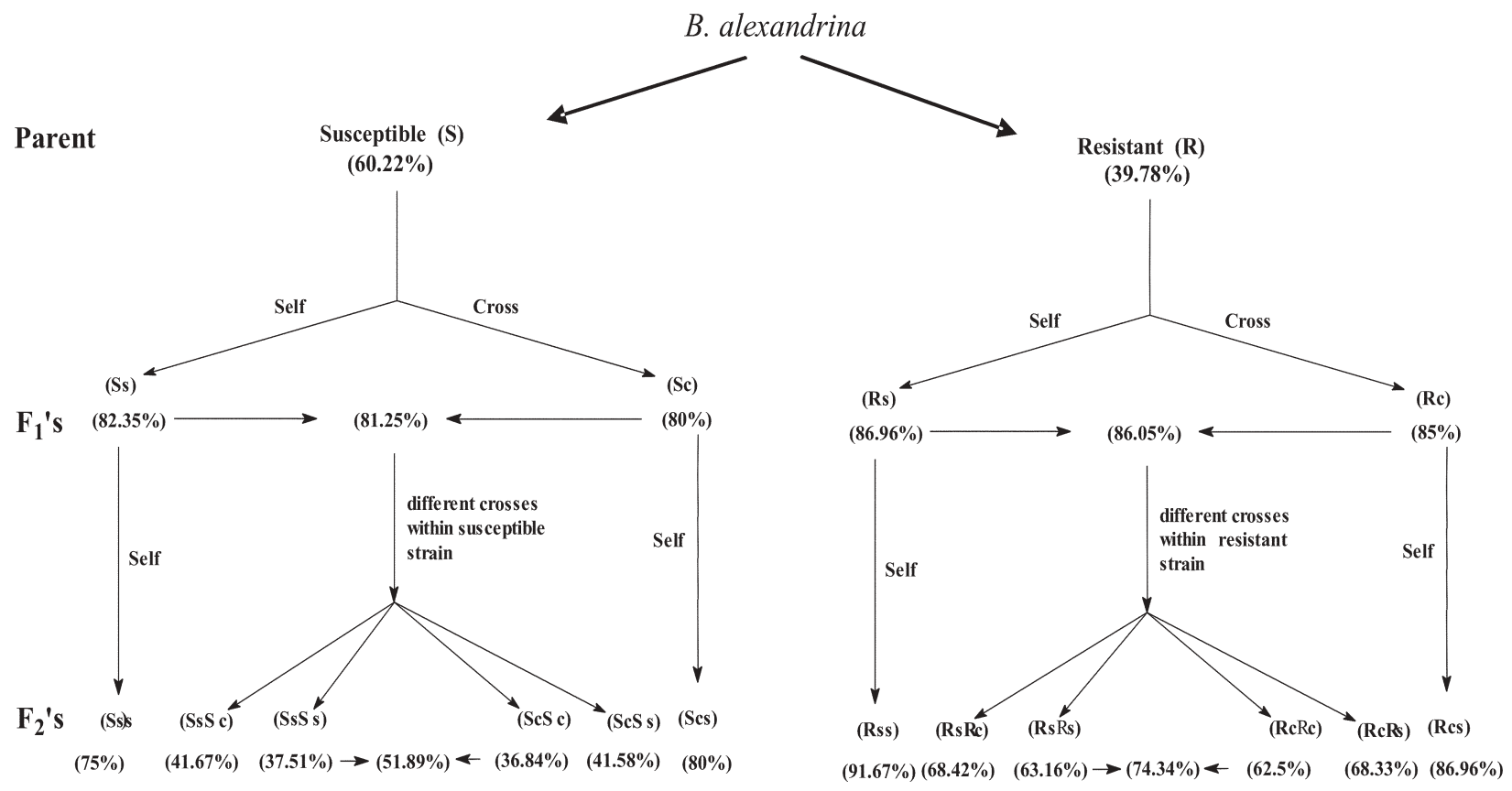

Fig. 2: diagrammatic representation of susceptible/resistance characters within three successive generations of Biomphalaria snails. \%: percentages of infection; Ss: susceptible self; Sc: susceptible cross; Rs: resistant self; Rc: resistant cross. 
snails by selfing exhibits retarded parasite development while by crossing the percentage showed only $85 \%$. Also, susceptibility in susceptible parental stock is expressed in percentages of 82.4 and $80 \%$ for both selfing and crossing, respectively as shown in Fig. 2.

Meanwhile, the resistant character has increased from $87 \%$ in the 1 st generation to $91.7 \%$ of selfing after selfing in the second generation.

The results showed the stability of markers in individual samples of susceptible and resistant phenotype snails. Only some-minor differences were occasionally observed and concerned with intensity. Also, the present study showed that the characteristics genetic profiles of susceptible and resistant phenotype snails were inherited and maintained in all $\mathrm{F}_{2}$ susceptible offsprings (Figs 4, 5). On the basis of these results, the arbitrary primer OPA-02 represent invariant structural genotypic differences between all individuals of susceptible and resistant strains and there was apparent linkage in the inheritance of susceptibility/resistance from one generation to the next.

Our interest, however, was to identify only stable invariant genetic markers in our laboratory stocks. The present study showed that with the OPA-02 utilized primer, only a specific marker of $430 \mathrm{bp}$ was amplified in the resistant phenotype snails. While results from comparable experiments demonstrated that in all susceptible genotype individual snails, no strain-specific marker was discernable with the same primer. Our results also showed the average percentage of shared bands between each pair from the same strain (either susceptible or resistant) was $100 \%$ and between all possible pairs different strains was $96 \%$. However, the RAPD-PCR profiles of the same strains of laboratory-maintained $B$. alexandrina snails were highly homogeneous while profiles from two different strains showed a degree of genetic variability.

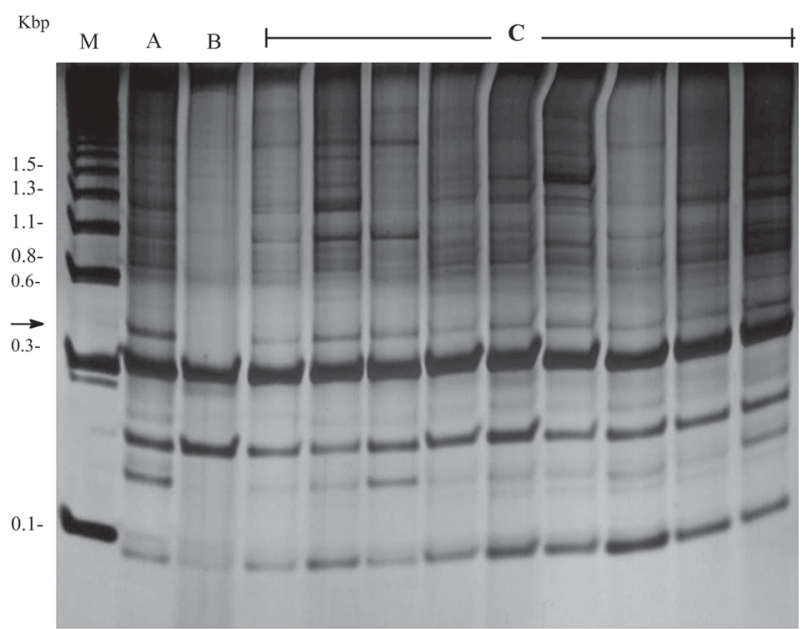

Fig. 4: polyacrylamide gel electrophoresis demonstrates heritance pattern of OPA-02 random amplified polymorphic product from parental $\mathrm{F}_{1}$ resistant phenotype snail (lane A) to nine individuals of $F_{2}$ offspring individual snails (lanes C). M: 123 bp DNA ladder; lanes-A: amplified fragments of parental $\mathrm{F}_{1}$ resistant phenotype snail; B: amplified fragments of parental $\mathrm{F}_{1}$ susceptible phenotype snail; $\mathrm{C}$ : amplified fragments of nine individuals of $\mathrm{F}_{2}$ offspring snails; arrow indicates the position of specific resistant marker at $430 \mathrm{bp}$ fragment.

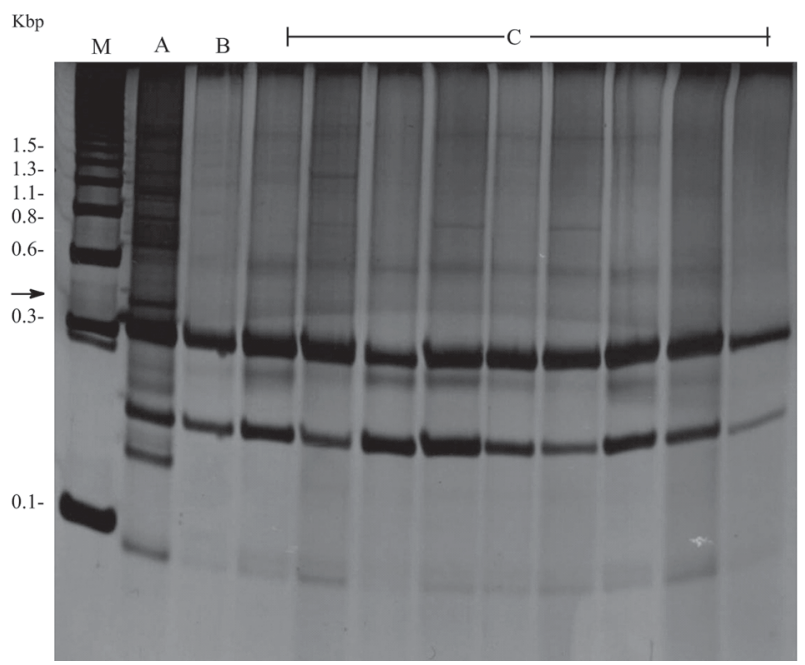

Fig. 5: polyacrylamide gel electrophoresis demonstrates heritance pattern of OPA-02 PCR product from parental $\mathrm{F}_{1}$ susceptible phenotype snail (lane $\mathrm{B}$ ) to nine individuals of $\mathrm{F}_{2}$ offspring individual snails (lanes C). M: $123 \mathrm{bp}$ DNA ladder; lanes- A: amplified fragments of parental $\mathrm{F}_{1}$ resistant phenotype snail; $\mathrm{B}$ : amplified fragments of parental $\mathrm{F}_{1}$ susceptible phenotype snail; $\mathrm{C}$ : amplified fragments of nine individuals of $\mathrm{F}_{2}$ offspring snails; arrow indicates the position of specific resistant marker at $430 \mathrm{bp}$ fragment.

\section{DISCUSSION}

It is widely acknowledged that an integrated approach is required to bring about a long-lasting reduction in schistosomiasis transmission as reported by WHO (2002). One promising component of control is the introduction of parasite-resistant snails into endemic areas to replace the resident, susceptible snails and to avoid the often destructive changes in the local ecosystem that accompany other forms of snail control.

Incompatibility (refractory character) of $B$. alexandrina to $S$. mansoni infection could be a heritable character like susceptibility. Consequently, it would be beneficial to select actively resistant snails and mass culture them to increase the proportion of alleles for Incompatibility as a possible mean for biological control of schistosomiasis in natural population.

The present results confirmed the hypothesis that $B$. alexandrina snails have high efficiency as intermediate hosts for S. mansoni parasites and play a potential role in transmission of schistosomiasis in Egypt.

In the present work, attempts were made to compare the susceptibility/resistance of three successive generations from bred laboratory $B$. alexandarina snails. However, the level of susceptibility/resistance varied among snails from one group to the other and from one generation to the other within the same snail strain according to the type of fertilization. These differences in the degrees of susceptibility are expected, since it was previously reported by Knight et al. (2000) that there were different genetic strains of a single species of snails from the same locality and they varied in their degrees of resistance and even among susceptible stocks, certain individuals were more resistant than others. This is in 
accordance with the findings by Woodruff (1985) who suggested the founding of such refractory population of Bulinus africanus under field conditions. In addition, Joubert et al. (1990) reported that one might assume the existence of partially or completely refractory snail population in nature among $B$. africanus population.

It is believed that the offspring obtained from self fertilization is presumed to result in a high degree of homozygosity while offspring obtained from crossfertilization is presumed to result in a high degree of heterozygosity (Newton 1955). Based on these studies and our finding, it can be concluded that the production of successive generation of snails by self-fertilization may have reduced the amount of genetic heterogeneity through inbreeding.

A probable explanation for the decrease in susceptibility from one generation to the next among snail progenies originated from laboratory bred $B$. alexandrina is that the parent snails carry many genes for insusceptibility character and the alleles for insusceptibility increased among successive generations. Based on our findings and the studies of Richards (1984) and Richards and Shade (1987), it can be concluded that Incompatibility (refractory character) of $B$. alexandrina to $S$. mansoni infection may be a heritable character controlled by genetic factor like susceptibility.

The likelihood that the genetic diversity of the intermediate snail host affects schistosomiasis transmission in endemic areas, and the possibility of using refractory snails as a method of control, has been previously discussed in Brazil (Spada et al. 2002, Rosa et al. 2004). However, without methods to determine the frequency of resistant genes in field populations of snails, it will be extremely difficult to assess how feasible this snail control method could be. This study is the first of a series of studies from our laboratory applying molecular techniques to determine the extent of genetic diversity among well defined stocks of $B$. alexandrina with two different phenotypes with $S$. mansoni. The ability to determine resistant or susceptible markers in our laboratory-maintained $B$. alexandrina snails would be an important component of studies to potential biological control measures employing the use of refractory snails.

In a comparable study, Vidigal et al. (1994) indicated that the RAPD profiles of DNA genome of B. glabrata snails of the same strain were relatively homogenous, with the majority of common bands. In contrast, the profiles of snails from different strains were quite distinct. Also, Abdel-Hamid et al. (1999) demonstrated that there are very limited differences in the amplified bands of $B$. tenagophila resistant or susceptible and the only reproducible differences noticed were between the two strains of snails.

The present work showed that the arbitrary primer, OPA-02, amplification DNA samples of individual resistant phenotype snails identified a $430 \mathrm{bp}$ strain-specific fragment. This molecular marker was inherited in a dominant fashion in the resistant $\mathrm{F}_{1}$ and $\mathrm{F}_{2}$ segregating progenies.

In this respect, the present results confirmed the observations of Knight et al. (1999) who identified molecular markers associated with resistance in $B$. glabrata genome and showed that both the $1.2 \mathrm{~kb}$ marker amplified by primer OPM-04 and $1.0 \mathrm{~kb}$ marker produced by primer OPZ-11 segregated and inherited in the same dominant fashion.

Similar results were obtained by Lewis et al. (1997) who reported that certain strain specific markers were inherited in a co dominant fashion in the majority of $\mathrm{F}_{2}$ B. glabrata snail progeny under their utilized primer. They obtained DNA from $\mathrm{F}_{2}$ progeny from crosses between parasite-resistant and susceptible $B$. glabrata snails, searched for molecular markers that show linkage to either the resistant or susceptible phenotype. Using both RFLP and RAPD approaches revealed that more promising results have been found with RAPD approach, where a $1.3 \mathrm{~kb}$ marker appears in nearly all resistant progeny, and a $1.1 \mathrm{~kb}$ marker appears in all susceptible progeny.

These results represent a starting point for the identification and isolation of gene or gene product specifically related to the resistance of Schistosoma parasite in their respective hosts.

\section{REFERENCES}

Abdel-Hamid AZ, Molfetta JB, Fernandez V, Rodrigues V 1999. Genetic variation between susceptible and non-susceptible snails to Schistosoma infection using random amplified polymorphic DNA analysis (RAPDs). Rev Inst Med Trop São Paulo 41: 291-295.

Coelho PMZ, Carvalho OS, Andrade ZA, Martins-Sousa RL, Rosa FM, Barbosa L, Pereira CAJ, Caldeira RL, JannottiPassos LK, Godard ALB 2004. Biomphalaria tenagophila/ Schistosoma mansoni interaction: premises for a new approach to biological control of schistosomiasis. Mem Inst Oswaldo Cruz 99: 109-111.

Da Silva D, Sobral-Hamaguchi S, Spada RGM, Abdel-Hamid AZ, Zuim NRB, Zanotti-Magalhaes EM, Magalhães LA, Ribeiro-Paes JT 2004. Biomphalaria tenagophila: genetic variability between intermediate snail hosts susceptible and resistant to Schistosoma mansoni infection. Parasite 11: $35-42$.

El-Khoby T, Galal N, Fenwick A 1998. The USAID government of Egypt schistosomiasis research project (SRP). Parasitol Today 14: 92-96.

Joubert PH, Kruger FJ, Pretorious SJ 1990. Susceptibility of South Africa Bulinus africanus populations to infection with Schistosoma haematobium. Trans R Soc Trop Med Hyg 84: 100-102.

Joubert PH, Pretorious SJ, Kruger FJ 1991. Further studies on the susceptibility of Bulinus africanus to infection with Schistosoma haematobium. Ann Trop Med Hyg 85: 253-258.

Knight M, Miller NA, Patterson CN, Rowe CG, Michaels G, Carr D, Richards CS, Lewis FA 1999. The identification of markers segregating with resistance to Schistosoma mansoni infection in the snail Biomphalaria glabrata. Proc Natl Acad Sci USA 96: 1510-1515.

Knight M, Ongele E, Lewis FA 2000. Molecular studies of Biomphalaria glabrata, an intermediate hosts of Schistosoma mansoni. Inter J Parasitol 30: 535-541. 
Lewis FA, Knight M, Richard CS 1997. A laboratory-based approach to biological control of snails. Mem Inst Oswaldo Cruz 92: 661-662.

Lotfy WM, DeJong RJ, Black BS, Loker ES 2005. Specific identification of Egyptian Biomphalaria species and possible hybrids using the polymerase chain reaction based on nuclear and mitochondrial loci. Mol Cell Prob 19:21-25.

Newton WL 1955. The establishment of a strain of Australorbis glabratus which combines albinism and high susceeptibility to infection with Schistosoma mansoni. J Parasitol 41: 526528.

Richards CS 1984. Influence of snail age on genetic variation in susceptibility of Biomphalaria glabrata for infection with Schistosoma mansoni. Malacology 25: 493-503.

Richards CS, Shade PC 1987. The genetic variation of compatibility in Biomphalaria glabrata and Schistosoma mansoni. J Parasitol 73: 1146-1151.

Rollinson D, Stothard JR, Jones CS, Lockyer AE, de Souza CP, Noble LR 1998. Molecular characterization of intermediate snail hosts and the search for resistance genes. Mem Inst Oswaldo Cruz 93: 111-116.

Rosa FM, Caldeira RL, Carvalho OS, Godard ALB, Coelho PMZ 2004. Dominant character of the molecular marker of Biomphalaria tenagophila strain (Mollusca: Planorbidae) resistant to Schistosoma mansoni. Mem Inst Oswaldo Cruz 99: 85-87.

Santos FR, Pena SDJ, Epplen JT 1993. Genetic and population study of a Y-linked intranucleotide repeat DNA polymorphism.
Hum Gen 90: 655-656.

Simpson AJG, Dias Neto E, Steindel M, Caballero OLSD, JanottiPassos LK, Pena SDJ 1993. The use of RAPDs for the analysis of parasites. In SDJ Pena, DNA Fingerprinting State of the Sciences, Birkhauser, Cambridge, MA, p. 331-337.

Spada RG, Silva D, Abdel-Hamid AZ, Sobral-Hamaguchi S, Zuim NR, Zanotti-Magalhaes EM, Magalhães LA, Ribeiro-Paes JT 2002. Genetic markers between Biomphalaria glabrata snails susceptible and resistant to Schistosoma mansoni infection. Mem Inst Oswaldo Cruz 97: 53-58.

Vidigal TH, Neto ED, Carvalho OS, Simpson AJG 1994. Biomphalaria glabrata: extensive genetic variation in Brazilian isolates revealed by random amplified polymorphic DNA analysis. Exp Parasitol 79: 187-194.

Winnepenninckx B, Backeljau T, Wacbier R 1993. Extraction of high molecular weight DNA from mollusca, Trends Genetics 9: 407.

Woodruff DS 1985. Genetic control of schistosomiasis: a technique based on the genetic manipulation of intermediate host snail populations. Comp Pathobiol 8: 41-68.

WHO-World Health Organization 2002. Prevention and control of schistosomiasis and soil-transmitted helminthiasis. Tech Rep Ser 912: 1-57.

Zanotti-Magalhães EM, Magalaes LA, Carvalho JR 1997. Relação entre patogenicidade do Schistosoma mansoni em camundongos e a susceptibilidade do molusco vetor. IV. Infecciosidade dos miracidios. Rev Saúde Pública 29: 265-270. 